\title{
Ocular Lyme disease: case report and review of the literature
}

\author{
Danny J H Kauffmann, Gary P Wormser
}

\begin{abstract}
Lyme disease is an emerging new spirochaetal disease in which ocular complications may arise. We have seen a 45-year-old woman who developed unilateral endophthalmitis leading to blindness during the course of this disease. Ocular tissue showed the characteristic spirochete. A literature review shows that the commonest ocular manifestation of Lyme disease is a mild conjunctivitis, but other symptoms may include periorbital oedema, oculomotor palsies, uveitis, papilloedema, papillitis, interstitial keratitis, and others. Ophthalmologists treating patients from Lyme disease endemic areas need to be aware of the protean clinical manifestation of this disease.
\end{abstract}

Lyme disease, a tick-borne spirochaetal infection, ' often begins with a characteristic rash, erythema chronicum migrans..$^{23}$ Ocular manifestations have been infrequently reported, but, as the disease is increasing in frequency and occurring in new geographical areas, ${ }^{4}$ more cases with ocular involvement can be expected. We report in detail the eye findings in a patient previously reported on who developed severe, unilateral endophthalmitis five weeks after erythema chronicum migrans. ${ }^{5}$ Spirochaetes were found in the vitreous in specimens obtained at surgery. In addition we review the literature of the ocular and neuro-ophthalmic manifestations of Lyme disease.

\section{Case report}

On 15 July 1982 a 45 -year-old woman from Westchester County, New York, developed severe headache, light headedness, chills, and fever. Three days later she also had nausea and vomiting. On 21 July she noted red lesions on her right foot and upper arms that looked like insect bites. In addition a large annular erythema with an indurated centre was noted on the right thigh. This lesion expanded and developed a bright red outer border with central clearing. She remembered having been bitten by many flying insects during the 4 July weekend but recalled no tick bites. She was treated with diphenhydramine hydrochloride $50 \mathrm{mg}$ four times a day and a cortisone skin ointment for what was thought to be a local skin allergy to insect bites. On $30 \mathrm{July,}$ because of daily fevers, malaise, and skin lesions, she was admitted to a community hospital.

A physician removed fragments of a presumed insect stringer from her right foot accompanied by a white mucoid discharge. Her white blood cell count was $22 \times 10^{9} / 1$ with $73 \%$ polymorphonuclear leucocytes and $18 \%$ band forms, and the erythrocyte sedimentation rate was $48 \mathrm{~mm} / \mathrm{h}$. She was treated empirically with intravenous cefazolin, $6 \mathrm{~g}$ a day for seven days, but continued to have daily fevers up to $40 \cdot 1^{\circ} \mathrm{C}\left(104 \cdot 2^{\circ} \mathrm{F}\right)$. She was then changed to oral tetracycline, $500 \mathrm{mg}$ four times a day for seven more days. She responded well to this regimen.

Two weeks later, on 25 August 1982, a sting on the left thigh by a bee caused local erythema. Two days afterwards she awoke with a painful red left eye. She had no eye complaints previously. The patient treated herself with sulphafurazole (sulfisoxazone)drops, but sought an ophthalmologist when the vision decreased in the left eye and periorbital oedema developed. She was noted to have iritis and posterior synechiae and was treated with topical atropine 1\% and Predforte 1\% (dexamethasone) drops, with resultant breaking of the synechiae. However, the iritis persisted, and despite subconjunctival injection of triamcinolone $40 \mathrm{mg}$ hypopyon developed along with vitritis. Oral prednisone $60 \mathrm{mg}$ per day was begun. The visual acuity nevertheless worsened, and the prednisone dose was increased to $100 \mathrm{mg}$ daily. She was then transferred to Westchester County Medical Center.

Her visual acuity was 20/20 right eye and hand motions left eye. The results of ocular examination including tension were normal in the right eye. The left eye showed mild conjunctival ecchymosis and ciliary vessel injection. There was mild periorbital oedema. The ocular rotations were full, though splinting of the left eye was noted in extreme fields of gaze. There was no measurable proptosis. The cornea showed microscopic epithelial oedema with stippled fluorescein staining. There was a severe inflammatory reaction in the anterior chamber, with $3+$ flare and cells, and a $20 \%$ hypopyon was present. After dilatation of the pupil pigment residua were noted on the anterior lens surface from the previously treated posterior synechiae. The lens was otherwise clear. The ocular tension was $18 \mathrm{mmHg}$. The left fundus could not be seen, and no red reflex was obtained through the cellular debris in the media. Ophthalmic A and B scan ultrasound revealed diffuse debris in the vitreous cavity, with marked thickening of the choroid consistent with a 
TABLE I Ophthalmic and neuro-ophthalmic manifestations of Lyme disease

Optic neuritis

Optic perineuritis

Ischaemic optic neuropathy

Optic atrophy

Cranial nerve palsies

Argyll-Robertson pupil

Pupillary areflexia

Pupillary areflexia

Cortical blindness

Papilloedema

Conjunctivitis

Keratitis

Iritis

Iridocyclitis

Panuveitis

Vitritis

Choroiditis

Exudative retinal detachments

Retinal vasculitis

Retinal haemorrhages

Periorbital oedema severe panophthalmitis. The retina was attached.

The initial impression was severe uveitis of unknown aetiology. Prednisone was continued at $100 \mathrm{mg}$ daily and tapered to $60 \mathrm{mg}$ over the next seven days. Roentgenograms of the chest, skull, sinuses, orbits, and sacroiliac joints were normal. Serological tests for syphilis (FTA-abs, VDRL), antinuclear antibodies, angiotensin converting enzyme, cryoglobulins, rheumatoid factor, toxocara, toxoplasmosis, histoplasmosis, and cytomegalovirus were negative. A 5 TU tuberculin skin test was negative. Serum creatinine and liver enzymes were normal. Serum obtained on $17 \mathrm{Sep}-$ tember 1982 showed an IgM antibody titre to the Lyme spirochaete of 1:64 and an IgG titre of 1:512 (normal for both $<1: 64$ ) determined by indirect immunofluorescence.

Eight days after admission to hospital and while on prednisone $60 \mathrm{mg}$ daily the patient developed a rapid rise in intraocular pressure in the left eye to $40 \mathrm{mmHg}$ along with $5 \mathrm{~mm}$ proptosis, a conjunctival purulent discharge, and the rapid onset of a dense cataract. Computerised tomography showed no evidence of a lesion to explain the proptosis. Orbital cellulitis was suspected, and nafcillin $12 \mathrm{~g} /$ day plus gentamicin $80 \mathrm{mg}$ every eight hours was given intravenously along with topical neomycin-polymixin B (Neosporin) and dexamethasone. The ocular tension was controlled with acetazolamide $1 \mathrm{~g}$ orally daily and timolol $0.5 \%$ topically. Conjunctival cultures were negative for bacteria, fungi, and mycobacteria.

One week later, 19 days after admission, a lensectomy and vitrectomy were performed and purulent vitreous material was removed. Intravitreal gentamicin $0.2 \mathrm{mg}$ in $0.1 \mathrm{ml}$ and chloramphenicol $0.2 \mu \mathrm{g}$ in $0.1 \mathrm{ml}$ were injected and systemic antibiotics were maintained, while systemic steroids were tapered. Cultures and smears for bacteria, fungi, and acid fast organisms were negative, and cytological examination of a fresh vitreous specimen revealed only white cells. One week later a second vitrectomy to remove increasing amounts of vitreous debris was performed. Examination of the material by dark field microscopy was negative for spirochaetes.

Pathological examination of the lens and vitreous contents showed lens fragments and necrotic cells with a heavy infiltration of mononuclear cells. Later the eye tissue was stained by the Dieterle method. ${ }^{6}$ Despite the advanced cell necrosis, occasional intact spirochaetes, morphologically compatible with the Lyme spirochaete, were demonstrated in vitreous material.

After surgery the patient continued to have mucous secretions from the eye and experienced occasional myalgias and arthralgias. A good red reflex was obtained, vision returned to hand motions, and on 13 October she was discharged from hospital. However, over the ensuing three months she developed a dense cyclitic membrane in her eye and lost all functional visual activity, with the eye becoming phthisical. On 28 October IgM antibody to the spirochaete was no longer detectable, and the titre of specific IgG had decreased to 1:64. By May 1983 neither specific IgM not IgG antibody was found. After one year the patient was given a cosmetic contact lens shell covering the phthisical left eye. She developed no manifestation of Lyme disease in her right eye, which continuously maintained $20 / 20$ vision throughout the course of her disease.

\section{Discussion}

Our patient presented with a uniocular uveitis due to Lyme disease which progressed to a panendophthalmitis and ultimate destruction of useful uniocular vision. ${ }^{5}$ Other examples of Lyme related uveal tract involvement include case reports of patients with iritis, ${ }^{7}$ uveitis, ${ }^{89}$ and choroiditis with exudative retinal detachment. ${ }^{10}$ The visual outcome of the other reported cases was much better. A patient with iritis had spontaneous resolution, and visual acuity in the others improved after the use of specific systemic antibiotics with $^{8}$ or without ${ }^{910}$ concomitant ocular steroids.

Additional ocular manifestations of Lyme disease include conjunctivitis, photophobia, periorbital oedema, cranial nerve palsies, keratitis, pupillary abnormalities, papilloedema, optic neuritis, and optic atrophy (Table I).$^{3911-24}$ The commonest ocular finding in Lyme disease appears to be conjunctivitis. Steere $e t$ al in a study of 314 patients with erythema chronicum migrans noted conjunctivitis in 35 (11\%), photophobia in $19(6 \%)$, and periorbital oedema in $10(3 \%) .{ }^{3} \mathrm{Un}$ fortunately the authors did not elaborate further. By inference and from our anecdotal experience conjunctivitis is not very prominent in this disease and is short-lived.

Neurological complications in Lyme disease occur in approximately $10 \%$ of cases, and over half of patients with them have cranial nerve palsies, most commonly involving the seventh nerve. ${ }^{12}$ Oculomotor weakness is infrequent, but may be due to cranial nerve palsy of the III, IV, or VI cranial nerves. Such palsies may occur individually, or in combination with one another and/or with other neurological abnormalities. ${ }^{12}{ }^{14}$ Diplopia is the typical ocular complaint in these instances. Like other neuropathies, oculomotor weakness usually resolves within two weeks to five months after onset. ${ }^{12} 14$ Whether antibiotics improve the rate of recovery has not been established. ${ }^{25}$ One patient with an Argyll-Robertson pupil ${ }^{12}$ and another with a reversible Horner's syndrome ${ }^{26}$ have been reported on, and optic atrophy has been noted in several patients (see below). ${ }^{912} 2728$

Papilloedema of diverse causes has been seen occasionally. ${ }^{12-162022}$ It has been observed in a minority of Lyme disease patients with meningitis. ${ }^{1422}$ It is then typically bilateral and may be symptomatic, leading to complaints of blurred vision. It is of interest that the intracranial pressure is often not raised, so that the pathogenesis of this condition is obscure. Too few data are available to assess the natural history of papilloedema in Lyme disease meningitis, but antibiotic therapy appears to hasten the resolution of certain other clinical signs. ${ }^{29}$ In one report resolution of papilloedema was accompanied by the development of pigment epithelial mottling at the fovea, ${ }^{16}$ and in two other cases optic atrophy ensued. ${ }^{12}$

Papilloedema has also been reported in several Lyme disease patients who had increased intracranial pressure but no evidence of meningitis. ${ }^{15}$ Sixth nerve palsy was sometimes present in these 
patients. Cranial tomography failed to reveal mass lesions or enlarged ventricles resulting in a diagnosis of Lyme disease-associated pseudotumor cerebri for some of these patients. ${ }^{15}$ Antibiotics plus additional medications for reducing intracranial pressure have been useful therapeutically.

Anecdotal cases of optic neuritis ${ }^{14} 20$ and optic atrophy ${ }^{2728}$ possibly due to Lyme disease have been reported. Bertuch et al ${ }^{18}$ described a patient who developed progressive temporal pallor of the right optic disc six months after onset of an illness presumed to be Lyme disease. In addition Shechter ${ }^{17}$ described a patient who developed papillitis of the right eye with an inferior altitudinal visual defect three months after the onset of Lyme disease. Despite a course of high dose systemic corticosteroids, the left eye of this patient also became involved. The process eventually stabilised after a course of antibiotics plus corticosteroids. The author's diagnosis in this latter case was ischaemic optic neuropathy due to Lyme disease.

Other late ophthalmic manifestations of Lyme disease have been described. Corneal abnormalities presumed to be due to Lyme disease have been described in four patients who developed a form of interstitial keratitis six months to as long as five years after the diagnosis of Lyme disease. ${ }^{181921}$ None of these patients had other symptoms attributable to Lyme disease when the ocular disease was demonstrated, and all four had previously received antibiotic therapy for Lyme disease. The keratitis was characterised by scattered corneal opacities that occurred randomly within the corneal stroma from Bowman's membrane to Descemet's membrane, either unilaterally or bilaterally. Bilateral involvement of the cornea was noted in one case in which the corneal stroma was involved asymmetrically. ${ }^{19}$ In one patient minimal neovasculatisation was seen. ${ }^{19}$ Two patients were asymptomatic, one of whom was found to have diminished visual acuity on routine school screening; the other two patients complained of decreased vision. The keratitis responded to topical corticosteroids ${ }^{121}$ but apparently not to systemic or tropical antibiotics, ${ }^{18}$ which supports the conjecture that this process has an immunological rather than an infectious origin.

Eye involvement in Lyme disease shares certain similarities with that seen in syphilis. Syphilitic uveitis or iritis occurs in about $4 \%$ of patients with secondary syphilis, but may also follow inadequately treated primary syphilis or may be a part of tertiary syphilis. ${ }^{30}$ Keratoiritis is the commonest manifestation, but choroiditis, lenticular opacities, retinitis, and panophthalmitis may occur. ${ }^{30}$ The vitreous often shows multiple yellow-grey exudates, which tend to spread along retinal vessels. ${ }^{31}$ An important differentiating feature of syphilitic keratitis from that so far reported in Lyme disease is the early and massive neovascularisation of the cornea in syphilis. ${ }^{19}$

Most authors suggest treatment of ocular syphilis with high-dose intravenous penicillin, sometimes accompanied by systemic corticosteroids. ${ }^{31}$ However, steroids alone may be permissive to the spirochaete and are likely to worsen the condition. ${ }^{31}$ Similarly, steroids may have contributed to the marked severity of the ocular infection in our patient.

Lyme disease is an emerging infectious disease which may cause eye lesions requiring treatment. Ophthalmologists caring for patients from endemic areas need to be aware of its protean clinical manifestations.

The authors thank Mrs Shirley M Gamble and Ms Susan Friedlander for their valuable assistance in preparing this manuscript and Dr Jorge Benach for performing the Lyme serological tests.

1 Steere AC, Grodzicki RL, Kornblatt AN, et al. The spirochetal etiology of Lyme disease. $N$ Engl F Med 1983; 308: 733-40.

2 Steere AC, Malawista SE, Hardin JA, Ruddy S, Askenase PW, Andiman WA. Erythema chronicum migrans and Lyme arthritis: the enlarging clinical spectrum. Ann Intern Med 1977; 86: 685-98.

3 Steere AC, Bartenhagen NH, Craft JE, et al. The early clinical manifestations of Lyme disease. Ann Intern Med 1983; 99: 76-2.

4 Schmid GP. The global distribution of Lyme disease. Rev Infect Dis 1985; 7: 41-50.

5 Steere AC, Duray P, Kauffmann DJH, Wormser G. Unilateral blindness caused by infection with the Lyme disease spirochete, Borrelia burgdorferi. Ann Intern Med 1985; 103: 382-4. 6 Van Orden AE, Greer PW. Modification of the Dieterle spirochete stain. F Histotech 1977; 1: 51-3.

7 Eichenfield AH, Goldsmith DP, Benach JL, et al. Childhood Lyme arthritis: experience in an endemic area. $\mathcal{F}$ Pediatr 1986; 109: 753-8.

8 Wong T. The onset of bilateral uveitis in an elderly man with fever, headache, and a rash. Ophthalmic Surg 1989;20: 154-6.

9 Winward KE, Smith JL. Ocular disease in Caribbean patients with serologic evidence of Lyme borreliosis. $\mathcal{F}$ Clin Neuro Ophthalmol 1989; 9: 65-70.

10 Bialasiewicz AA, Ruprecht KW, Naumann GOH, Blenk H. Bilateral diffuse choroiditis and exudative retinal detachments with evidence of Lyme disease. Am F Ophthalmol 1988; 105: 419-20.

11 Pachner AR, Steere AC. The triad of neurologic abnormalities of Lyme disease: meningitis, cranial neuritis, and radiof Lyme disease: meningitis, cranial

12 Reik L, Burgdorfer W, Donaldson JO. Neurologic abnormalities in Lyme disease without erythema chronicum migrans. Am $\mathcal{F}$ Med 1986; 81: 73-7.

13 Ackermann R, Horstrup P, Shmidt R. Tick-borne meningopolyneuritis (Garin-Bujadoux, Bannwarth). Yale f Biol Med 1984; 57: 485-90.

14 Reik L, Steere AC, Bartenhagen NH, Shope RE, Malawista SE. Neurologic abnormalities of Lyme disease. Medicine 1979; 58: 281-94.

15 Raucher HS, Kaufman DM, Goldfarb J, Jacobson RI, Roseman B, Wolff RR. Pseudotumor cerebri and Lyme disease: a man B, Wolff RR. Pseudotumor cerebri and

$16 \mathrm{WuG}$, Lincoff H, Ellsworth RM, Haik B. Optic disc edema and Lyme disease. Ann Ophthalmol 1986; 18: 252-5.

17 Shechter SL. Lyme disease associated with optic neuropathy. Am F Med 1986; 81: 143-5.

18 Bertuch WA, Rocco E, Schwartz EG. Eye findings in Lyme disease. Conn Med 1987; 51: 151-2.

19 Baum L, Barza M, Weinstein P, Groden J, Aswad M. Bilateral keratitis as a manifestation of Lyme disease. Am $\mathcal{F}$ Ophthalmol 1988; 105: 75-7.

20 Farris BK, Webb RM. Lyme disease and optic neuritis. $7 \mathrm{Clin}$ Neuro Ophthalmol 1988; 8: 73-8.

21 Orlin SE, Lauffer JL. Lyme disease keratitis. Am $\mathcal{F}$ Ophthalmol $1989 ; 107: 678-9$.

22 Jacobson DM, Frens DB. Pseudotumor cerebri syndrome associated with Lyme disease. Am $\mathcal{F}$ Ophthalmol 1989; 107: 81 .

23 Aaberg TM. The expanding ophthalmologic spectrum of Lyme disease. Am F Ophthalmol 1989; 107: 77-80.

24 Markowitz LE, Steere AC. Lyme disease during pregnancy. ¥AMA 1986; 255: 3394-6.

25 Clark JR, Carlson RD, Sasaki CT, Pachner AR, Steere AC. Facial paralysis in Lyme disease. Laryngoscope 1985; 95: $1341-4$.

26 Glauser TA, Brennan PJ, Galetta SL. Reversible Horner's syndrome and Lyme disease. $\mathcal{F}$ Clin Neuro Ophthalmol1989; 9: 225-8.

27 Schaltenbrand G. Durch arthropoden übertragene Infektionen der Haut und des Nervensystems. Munch Med Wochenschr 1966; 108: 1557 .

28 Schaltenbrand G. Durch arthropoden übertragene Erkrankungen des Haut und des Nervensystems. Verh Dtsch Ges Inn Med 1966; 72: 975

29 Steere AC, Pachner AR, Malawista SE. Neurologic abnormalities of Lyme disease: successful treatment with high dose intravenous penicillin. Ann Intern Med 1983; 99: 767-72.

30 Moore JE. Syphilitic iritis. Am f Ophthalmol 1931; 14: 110-22.

31 Ross WH, Sutton HFS. Acquired syphilitic uveitis. Arch Ophthalmol 1980; 98: 495-8.

32 Belin MW, Baltch AL, Hay PB. Secondary syphilitic uveitis. Am $\mathcal{f}$ Ophthalmol 1981; 92: 210-4. 